\title{
PARA HUMANIZAR HEIDEGGER: TRÊS VARIAÇÕES
}

\section{JULIANO GARCIA PESSANHA ${ }^{l}$}

RESUMO: O texto, dividido em três partes, apresenta de um modo heterodoxo aspectos centrais do pensamento heideggeriano e sua recepção por Peter Sloterdijk. A primeira parte procura mostrar que a semântica heideggeriana é deficitária quando se trata de esclarecer o enraizamento no mundo e que ela serve mais para designar o estar-suspenso-na-fronteira. $\mathrm{Na}$ segunda parte, discute-se o extremismo e o messianismo de Heidegger. Já a terceira fecha o texto aforismática e ironicamente com uma observação sobre sossego e desassossego.

PALAVRAS-CHAVE: Heidegger; recepção; Peter Sloterdijk

ABSTRACT: Divided into three parts, the text provides an unorthodox introduction to key aspects of Heideggerian thought and its reception by Peter Sloterdijk. The first part aims to show that Heideggerian semantics is deficient in throwing light on within-the-world rootedness and rather more fitting to mark being-suspended-in-the-boundary. The second part discusses Heidegger's extremism and messianism. Lastly, the third part brings the text to an aphoristic and ironic end, with a note on quietude and disquiet

KEY WORD: Heidegger; reception; Peter Sloterdijk

\section{A baleia e a ruptura}

Eu caminhava por uma cidadezinha do litoral uruguaio quando, de repente, deparei-me com um jardim perfumado e em seu centro havia um enorme esqueleto de baleia. O impacto foi tamanho que minha respiração se quebrou! A brancura dos ossos reluzia na noite azulmarinho. $\mathrm{O}$ ar estava puro e fresco, pois ali, na extremidade do continente, apenas um farol vigiava os mares. Fiquei durante muito tempo respirando perto do grande ossatura. Como podia aquele animal gigantesco, das profundezas do oceano, estar ali diante de mim numa brancura intacta? Um cão brincava e corria pelo interior oco dos ossos da baleia e eu me perguntava como é que junto daqueles dois animais, o vivo e o morto, havia ainda um terceiro, um animal retirado, exposto e capaz de acolher a beleza, desgrudá-la e soprá-la aos quatro ventos com palavras?

Foi esse pequeno evento que narrei a alguém que me pediu um esclarecimento sobre o pensamento de Heidegger. Eu disse que, se estivesse comigo em La Paloma, ele poderia

\footnotetext{
${ }^{1}$ Escritor e doutor em filosofia pela Universidade de São Paulo (USP). E-mail: julianogpessanha@hotmail.com.
} 
simplesmente contemplar a baleia e o jardim como paisagem e seguir indiferente, pensando talvez em alguma inovação decorativa para o seu próprio jardim, ou caso o seu QI ôntico fosse menos estético e ainda mais elevado, poderia medir os treze, catorze metros da baleia e calcular a quantidade de gordura e quantos ienes os japoneses deixariam de ganhar, ou ainda considerar que aquele ente majestático era na verdade um mamífero superior...

Em todos esses casos, disse a ele, você estaria hipnotizado pela entitude do ente e teria esquecido o rasgo da diferença que há entre o ente e o mistério da sua manifestação. Em todos esses casos, você seguiria sua caminhada soberba e estaria apenas fazendo coro com o predomínio do esquecimento do ser. Mas, se no azul profundo daquele anoitecer, a "veemência do real mais belo que o imaginado"2 te tocasse cortando tua respiração, eu teria condições de começar a desmedir o teu QI ontológico. Isso porque a questão não é esquadrinhar, delinear e abrir a caixa-preta dos entes - coisa que o ocidente, hoje mundial, está em vias de realizar por completo - mas permanecer atento ao acontecimento maravilhoso de que o ente é! Assim, a baleia não é apenas a sua forma e a sua constituição elementar, o que constitui a refeição e a superficialidade dos estetas, mas ela é algo que indica a sua aparição, ela aponta para o evento dela ser, para a doação indizível dela mesma. Se o esteta contempla a coisa e se deleita em sua poltrona, o heideggeriano, suspenso, sente perplexidade diante do seu surgimento. Ao contrário do esteta, ele não esquece a ocultidade e a doação que se retrai ${ }^{3}$. Posso então agora começar a te dizer que quem mora no rasgo dessa diferença efetua em si mesmo o sentido e a vocação dos textos de Heidegger, quer esta pessoa tenha ou não lido o pensador alemão.

Heidegger tomado como atividade cultural ou como assunto acadêmico de "exegese competente" constitui um triste mal-entendido. Ler Heidegger é desdobrar em si mesmo a experiência da negatividade e aceitar o convite de migração para fora da experiência do ser como presença. Lido a partir do QI ontológico, Heidegger é uma chave ou uma senha para abrir a porta para o precipício. Na medida em que me deixo conduzir pelo caminho do seu pensar, termino por encontrar acolhimento no precipício e, aninhado no precipício - o que constitui uma posição paradoxal e rara -, experimento o sentido do ser, não mais metafisicamente como presença, mas como vinda e emergência. Eu ousaria te dizer então que é um heideggeriano aquele que carrega no corpo a memória do ser como um salto. Essa

\footnotetext{
${ }^{2}$ Palavras da poeta Sophia de Mello Breyner Andresen (ANDRESEN,2001, p. 179).

${ }^{3}$ A noção de diferença ontológica é central na obra de Heidegger: o ente (uma cadeira, um partido político, um animal, um número) é, mas este "é" (o ser) não é ele próprio um ente. Ele é um acontecimento, a fosforescência no dizer de Levinas, que incide e banha o ente. Para Heidegger, a tradição metafísica esquece o ser, pois recalca o enigmático desse acontecimento e tenta reduzi-lo ao ente.
} 
espécie de homem-orvalho guarda também em sua dor o saber de nosso exílio, pois no mundo tecnosférico da produção e autoprodução infinitas as coisas secam e perdem o orvalho. São instaladas prontas e, por meio desse "não-acontecimento", destituídas de qualquer nascedouro e movimentação. Se lido a partir do QI ôntico e da vontade de saber, Heidegger gera apenas uma obesidade conceitual e um tagarelar infinito e sem "e daí...?", lido a partir do QI ontológico, ele nos conduz a um the end, a um espaço de retração e descolamento de onde experimento as coisas como advento e chegada.

Se doravante digo as coisas guardando o movimento dessa eclosão a partir do oculto, então é a linguagem que fala em mim. Meu dizer já não é mais metafísico, não é nem etiquetagem representacional da mera presença de algo, nem expressão de alguma vivência interior. É um dizer silente e calado, pois ele não esquece a autorretração e o autoesquecimento do ser: "vazio e sem acontecimentos"4, como um recém-chegado ou um recém-nascido, volto para casa. Estou curado da errância metafísica! Eu, janela sem ninguém, tornei-me agora "um ser impessoal, sou simplesmente um espelho fiel do mundo" (TSVETÁIEVA, 2008, p. 143). Minha casa é a casa da extimidade, uma casa para os íntimos do estranho. Uma casa erguida na distância, pois o excessivo adentramento, o apoio no ente, rouba o lugar da visão real! Uma casa longe da casa dos homens, para os recuados que têm por missão dizer e guardar o que os adentrados não enxergam. A casa heideggeriana é uma casa rara, uma casa fronteiriça para moradores com identidade negativa. Afinal, apenas um simesmo-buraco pode sustentar a ressonância amorosa da autoepifania fisiocêntrica. Os seres muito mundificados e contextualizados carregam o seu si mesmo por toda parte e dispõe de óculos antropocêntrico-culturais para ressoar o mundo da arena humana.

Mas os vazios e os ocos, os estenógrafos do ser, conforme a palavra de Marina Tsvetaiéva, esses seres não identificados com o mundo e mais sintonizados com o invisível da sua doação, existiram clandestinamente em várias épocas. Pós-metafísicos e não metafísicos existiram e fizeram aparição minoritária tanto no interior da história do ocidente quanto fora dela. Monges taoístas e pessoas como Chuang $\mathrm{Zu}$ existiram fora da história do ser enquanto alguns místicos cristãos e mais proximamente pintores como Cézanne ou poetas feito Hölderlin e Tsvetáieva viveram constantemente essa outra relação com o mundo, relação de

\footnotetext{
${ }^{4}$ Palavras da poeta Marina Tsvetáieva (2008, p. 294). A passagem completa é: “Amigo, se a tudo isso você for indiferente, você estará vazio como eu estou. Vazio como a Música. Você, sem acontecimentos. Você, sem paredes. Você - fora de você - [...]. Para você será fácil morrer”.
} 
deixar ser e do agradecer5. Isso não significa, entretanto, que haverá um dia uma época alética, um novo (outro) começo no qual o estremecer do Dasein abriria uma nova clareira epocal, algo como se toda cidade do litoral uruguaio recebesse a medida não mais da dimensão produtiva ou das várias economias libidinais, mas da retração que concede a brancura do esqueleto, reluzindo na noite azul-marinho. Uma tal revolução do ser comparável ao advento do paradiso terrestre acontecia apenas na cabeça do revolucionário Martin Heidegger. Como diz sensatamente Sloterdijk, o pensar heideggeriano é ótimo para uma “época pós-missionária, pós-científica, pós-universalista e pós-voluntarista. Mas uma época assim não existe" (SLOTERDIJK, 2011, p. 38). Vale dizer que não há superação da metafísica e uma questão mais legítima é saber como conseguem viver ou obter alguma proteção jurídica os pastores do ser que vivem no interior do construtivismo agressivo da modernidade.

O relato do evento-baleia é topologicamente útil para clarificar a posição heideggeriana. Ele mostra, contrariando a afirmação propalada em manuais, teses e artigos, que Heidegger não é um pensador do ser-no-mundo. Ele, inclusive, nutria uma certa antipatia pelos mundanos e pelos esquecidos. Toda sua incitação filosófica aponta para o ser-nafronteira e para a experiência do acontecer original do mundo. Quer se tome o Ser e tempo ou o pequeno opúsculo Que é metafísica? ou ainda outro texto, sempre leremos que é apenas quando a familiaridade escorre para o ralo e o ente emerge na estranheza que se pode apreender a situação originária e o quem do Dasein. “[...] ser aí quer dizer: estar suspenso dentro do nada!" (HEIDEGGER, 1979a, p. 41). Estar suspenso dentro do nada ou "estar entre (Das Zwischen) o essenciar-se do ser e a entitude do ente". (HEIDEGGER, 2003, p. 29) Nada disso diz do estar dentro do mundo. Para o pensador de Freiburg, o estar caído e apoiado no ente equivale a um estar-em-pecado e o homem que coincide com a sua determinação mundana é para Heidegger sempre alguém suspeito de não ter percebido que se encontra sequestrado. É apenas quando ele descoincide da determinação mundana que ele pode ganharse novamente. Daí o privilégio concedido aos moribundos no pensamento heideggeriano:

\footnotetext{
A proposição apropriada no que diz respeito ao Dasein no seu ser deveria ser sum moribundus [eu sou morrendo], moribundus, não como alguém gravemente doente ou ferido, mas que enquanto eu sou, eu sou moribundus. O moribundus dá primeiro ao sum o seu sentido. (HEIDEGGER,1992, p. 317)
}

\footnotetext{
5 Na língua alemã, a palavra pensar (denken) deriva de agradecer (danken). O pastor do ser, equivalente heideggeriano do estenógrafo do ser, da poeta Marina Tsvetáieva, contrariamente ao senhor dos entes, é aquele que pensa agradecendo o favor de haver coisas.
} 
A diferença entre estar no mundo e já não mais estar nele - a primeira diferença explorada por Heidegger nos anos 1920 - assegura ao Dasein a constância da iniciação, o salto angustiado a partir do sem-apoio (Ab-Grund).

Se o moribundo é des (constituído) pela ruptura e pela diferença, o mesmo vale para a criança heideggeriana. Em Introdução à filosofia, curso de 1928-1929, ao tentar preencher a lacuna deixada em Ser e tempo, lacuna nomeada no $\$ 72$ da obra de $1927^{6}$ sobre o Dasein infantil e o ser-para-o-começo, mas também sobre o nexo da vida no qual o Dasein tem continuidade, Heidegger informa que a sua criança nasce do movimento de esquiva. $\mathrm{O}$ nascedouro do infante heideggeriano é o não. "Enquanto esses fenômenos como a repulsa, a rejeição, a defesa não forem esclarecidos em sua estrutura ontológica, não poderemos começar a interpretar um estado dessa natureza como o estado da criança em sua essência" (HEIDEGGER, 2008, p. 132). O menino heideggeriano surge esquivo. Onde está o sim jubiloso da criança que, acompanhada do aliado, sente estar criando o mundo? Onde está a criança que se estende, expandindo o seu corpo sobre o mundo?

Ora, se o moribundo está suspenso e descolado dos entes e a criança também existe, para o pensador de Freiburg, numa posição de suspensão oriunda do não e da retração, como nomear o homem estabilizado de meia-idade, o homem que coincide e acolhe positivamente a determinação mundana? Impossível. Para alguém capaz de pensar tão profundamente a ruptura e a diferença é impossível acessar o segredo da continuidade. Se tanto o moribundo quanto a criança heideggeriana habitam sempre o rasgo de um começo e de um clarão, o que dizer do já começado que continua e não desmorona de si a todo momento? Será que esse "esquecido" está excluído de toda propriedade e consistência? Como soletrar a dignidade dos homens identificados com o mundo e que não conhecem a experiência de ser ruptura e desmoronamento permanente? Obviamente, Heidegger jamais corrigiu os déficits enunciados no $\$ 72$ de Ser e tempo. Ele teria que nascer de novo para fazê-lo e, talvez, nem assim o conseguisse. Ao longo de sua obra, o elogio do mortal hipertrofiou-se ${ }^{7}$, e a semântica para os mundos efetivamente existentes tornou-se mais e mais pobre, bem como as palavras, nada

\footnotetext{
6"A morte é, no entanto, apenas o 'fim' do Dasein e, em sentido formal, apenas um dos fins que abrangem a totalidade do Dasein. O outro 'fim' é o 'começo', o 'nascimento'. Só o ente 'entre' nascimento e morte apresenta o todo que se procura. Desta forma, ficou 'unilateral' a orientação dada até aqui à analítica, apesar de tender para o ser-todo existente e de explicar, genuinamente, o ser-para-a-morte próprio e impróprio. O Dasein só se fez tema existindo, por assim dizer, 'para frente', deixando, com isso, 'para trás' de si todo o ter sido. Não apenas se desconsiderou o ser-para-o-começo, mas sobretudo, a extensão do Dasein entre nascimento e morte. Na análise do ser-todo, passou-se por cima do 'nexo da vida' em que o Dasein, constantemente e de algum modo, se mantém" (HEIDEGGER, 2006, p. 464). A tradução do trecho foi modificada a partir da edição citada.

${ }^{7}$ Hipertrofiou-se a ponto de ele encarnar a única esperança de um futuro outro e a única chance de historicidade para além das notícias historiológicas do homem normalizado do Gestell (armação). Esse último apenas o equivalente a uma nuvem de gafanhotos.
} 
lisonjeiras, dirigidas ao pobre escravo da armação (Gestell), que, no ápice do esquecimento, converte-se em mero títere do produtivismo cego.

$\mathrm{Na}$ verdade, o único modo de pensar a determinação mundana positivamente - não como um sequestro ou algo que desaba prontamente sobre um coletivo de camelos - é pensala como algo que emerge das relações fortes e do fenômeno da criação de mundo (fenômeno onde eu crio e sou criado por aquilo que encontro). Em Ser e tempo não há irmãos juramentados, casais apaixonados e muito menos bebês mordendo o peito de mães. Heidegger não pensou o espaço das relações íntimas nem explicitou fenomenologicamente aquilo que (efetivamente) acontece entre seres humanos. É certo que devemos a ele a desconstrução do entulho metafísico no qual se assenta inclusive a teoria psicanalítica, mas a desconstrução da relação sujeito/objeto não garante a descrição precisa daquilo que acontece no registro interhumano. Devemos isso a Peter Sloterdijk: sua descrição dos aliados e dos receptáculos imunológicos revela o núcleo mágico e o caroço surreal e abundante da experiência do si mesmo e do ser no mundo. A esferologia sloterdijkiana esclarece definitivamente a posição de Heidegger ${ }^{8}$.

Pode-se dizer que Martin Heidegger - se pensarmos em uma tríade de personagens conceituais ovoides -, é um pensador do ovo-cuia (o ovo cortado sem a parte superior) e do ovo blindado e duro (sem furos). Sua obra é um hino de louvor ao primeiro e uma tática militante para tentar furar e quebrar o segundo. Há, entretanto, uma limitação do pensador do originário para acessar a experiência e o locus do ovo inteiriço com furinhos. Nomear e compreender essa possibilidade de ser humano é o que logra Peter Sloterdijk. Sua analítica do estar-acompanhado, fundante da interioridade e da pessoalidade, localiza a posição solitária de Heidegger. À luz de Sloterdijk, Heidegger, o menino que perdeu o mundo para ganhar o olhar, é um gênio da solidão.

\section{A revolução}

Se abordarmos o pensamento de Heidegger a partir do repertório imunológico proposto por Sloterdijk, o que fica claro é que Heidegger rejeita tanto o design de tipo metafísico quanto o conjunto das imunidades modernas. Ele não se sente em casa nem no primeiro tipo nem no

\footnotetext{
${ }^{8} \mathrm{Na}$ sua trilogia, Sloterdijk avança a analítica do estar-no-mundo, pois, ao introduzir o termo esferas, ele consegue resolver pontos cegos da obra de Heidegger. Este último não esclarece o adentramento não alienado no mundo, nem a senha de entrada para nele enraizar-se. Tais questões dependem do desenvolvimento de uma semântica da intimidade e de uma análise da criação de mundo, o que só se logra com a explicação das díades que compõem as microesferas.
} 
segundo. Se a experiência fundamental no mundo metafísico é a da apreensão intelectual da coisa na sua forma aspectual, forma essa que, ao perdurar imune ao sensível e ao devir, lança a alma que a contempla no abrigo do eterno, a experiência moderna fundamental da entitude do ente é a representabilidade. Isso quer dizer que o ente só aparece na medida em que é colocado por um sujeito e obedece à sua legislação interiorizada. O sujeito humano é a condição do objeto e objetividade é exatamente a situação na qual o ente encontra-se sob a jurisdição do sujeito moderno. Ora, Heidegger rejeita tanto a metafísica platônica, que conduz ao endereço verdadeiro no suprassensível, quanto o programa teórico gnosiológico moderno, que faz do ente um prisioneiro do olhar do homem sobre ele. Nesse segundo programa, a Terra é paulatinamente convertida num condomínio de bem-estar que se autogere. Para Heidegger, a casa e a pátria não estão nem no além nem no mundo instalado provedor de conforto e "qualidade de vida". O filósofo de Freiburg pretendia reivindicar um terceiro tipo de experiência que não concedia a estabilidade da theoría grega nem o controle oriundo da investigação científica. Nem céu, nem laboratório! Esses dois mundos constituem exílio para aquele que guarda a memória da pátria. Estar longe de casa e de nós mesmos; isso está patenteado na experiência da dor. A dor sustenta a memória da reconciliação. A dor recorda a nossa distância da coisa (como advento, como mensageira) do outro (como vizinho do mistério) e de nós mesmos (como receptáculos ocos). A dor atinge o ápice na apatridade (Heimatlösigkeit). São sintomas dessa apatridade: a "interpretose" infinita das ciências humanas e a sua fobia da verdade; a imortalidade galopante nas ciências da vida e a conquista cósmica na ciência natural. Diante dessa aceleração desenraizadora, só a dor encarnada no pastor do ser constitui ainda uma salvaguarda do ethos originário. Mas o que guardam o mortal e o pastor do ser? E a resposta é: eles guardam o simples, a maravilha das maravilhas, o acontecimento fundamental de que o ente é.

Se os metafísicos, antigos ou modernos, ficam detidos na onipresença do ente, seja para saudá-lo conceitualmente seja para protetizá-lo ou melhorá-lo tecnicamente, o pósmetafísico reivindica o retorno à casa. Retornar para a casa e curar-se da errância metafísica significa tanto ultrapassar a posição subjetiva quanto entrar em uma relação modificada com a linguagem. Aquele que já não experimenta apenas o delineamento do ente, mas habita o clarão da eventualização do ser, já não é um titular ou um proprietário de suas palavras. É a linguagem do ser que fala através dele, como se este último dispusesse de um aliado estranho cuja essência é exatamente ser canal aberto e desentupido para o ressoar dizente da oferta incessante do "dá-se”. (HEIDEGGER, 1979b, p. 284) 
O que salta aos olhos na caracterização do pastor do ser é o extremismo dessa posição. Quantos candidatos apareceriam num RH de seleção para pastores do ser ou mortais heideggerianos? A escassez dos candidatos repousa em que as figuras mencionadas não são nem de reflexão nem da interioridade. Quem toma seriamente o caminho de Heidegger diz não ao belo e ao mundo estético, ao mundo eterno e também ao mundo interno. Diz não também à investigação científica e às suas construções, só restando como maneira de viver uma vagabundagem poético-ontológica fiel à palavra dizente. Aliás, a primeira vez que compreendi Heidegger, eu assistia a um filme na televisão sobre um policial que sofria de amnésia e queria descobrir qual era a sua identidade. Se ele era do grupo do bem ou do mal. A certa altura cai um pé d'água e passa uma mulher com um guarda-chuva. Nessa hora eu me levantei da poltrona e gritei: Diz a chuva, diz a mulher! Esquece de vez este assunto de querer saber quem você é! Você é feito para dizer, ressoar e desaparecer! Aproveite que se esqueceu do entulho biográfico, agarre esta oportunidade nadificante e faça algo diferente! Tome o oco, o vazio e a facilidade para morrer. É óbvio que o filme não foi nesta direção, mas esta intervenção explica porque Sloterdijk (2007) em $O$ sol e a morte se refere a Heidegger como o fundador de uma religião da clareira, religião cujo ensinamento único é o de que o homem deve acolher reverentemente o clarão inquietante e meditá-lo. Não há dúvida de que uma figura como essa, desfigurada e em questão, pois já não pode dizer quem é e onde está, teria dificuldade em encontrar um lugar ôntico no mundo moderno onde o que importa é a explicação dos entes, a explicitação dos processos e a reconstrução da totalidade das coisas. Como já não resta quase nada do brotar fisiocêntrico para a colheita do pastor do ser, e tudo o que é encontra-se emoldurado pela armação, o pastor do ser, para não secar de aridez e emudecer de dor, precisa ser transplantado para reservas e parques de natureza naturante, mas essas zonas são doravante elas mesmas calculadas e desenhadas pela técnica e protegida por governos organizados.

$\mathrm{Na}$ verdade, a famosa revolução heideggeriana, a transição da gramática humanista do ativismo para a "gramática do acontecimento", jamais acontecerá (SLOTERDIJK, 2007, p. 88). Se Heidegger conseguia acreditar no seu próprio mantra da cesura epocal, das ilusões revolucionárias humanas (comunismo e nazismo) para a verdadeira revolução ontológica da religião da clareira, nós, oitenta anos depois, já não temos mais como não sorrir do pensador alemão e da sua narrativa da superação da metafísica. Esse relato filosófico, no qual o "niilismo europeu" poderia não ser a estação terminal, é hoje mero assunto acadêmico para a estante dos clássicos e os conversadores de segunda ordem nos guichês universitários. 
Quando se nota as ondas de refugiados e imigrantes buscando as áreas de conforto e proteção no âmago do "niilismo europeu" e nas cidades mais opulentas do último homem, fica evidente que o temor heideggeriano (e também o de Nietzsche) da ausência de futuridade inaugurada pela pós-história era fundamentalmente cristão.

Se a revolução de Marx, uma revolução que abolisse a troca mercantil e o predomínio do trabalho abstrato e do valor sobre a vida concreta, esteve longe de acontecer, a revolução de Heidegger, igualmente extrema, pode ainda acontecer para alguém decidido a morar nos mosteiros do Monte Atos ou n'alguma ilha do arquipélago japonês, onde exista comunidades de butô, mas essas hiperminorias já não abrirão futuros e rachaduras epocais no interior cronificado da tecnosfera. Se alguns poucos seres ex-postos dizem encontrar amparo no desamparo, esses serão sempre uma autovanguarda de eleitos sem seguidores. A maioria das pessoas continuará a buscar as imunidades oferecidas pela modernidade e a integração na atualidade infindável do habitáculo técnico.

\section{As mulheres}

Heidegger, o campeão do negativo e mestre do retraimento, gostava mesmo era dos mergulhos clandestinos nos corpos das mulheres. Se ele tivesse ousado pensar este outro movimento, concluiria que a suspensão imposta pela angústia é cansativa, que o amor é uma promessa de sossego (repouso) e que sua filosofia jamais se aproximou do verdadeiro segredo dos desenraizados (desassossegados).

\section{REFERÊNCIAS BIBLIOGRÁFICAS}

ANDRESEN, Sophia de Mello Breyner. Antologia: Mar. Lisboa: Caminho, 2001.

HEIDEGGER, Martin, Aportes a la filosofia: Acerca del evento. Buenos Aires: Biblos: Biblioteca Internacional Heidegger, 2003.

. "Carta sobre o humanismo", in Heidegger, trad. Ernildo Stein. São Paulo: Abril Cultural, 1979. (Coleção Os Pensadores.)

. History of the Concept of Time: Prolegomena, trad. Theodore Kisiel. Indianapolis: Indiana University Press/ Midland Book, 1992. 2008 .

. Introdução à filosofia, trad. de Marco Antonio Casanova. São Paulo: Martins Fontes,

. "Que é metafísica?", in Heidegger, trad. Ernildo Stein. São Paulo: Abril Cultural, 1979a. (Coleção Os Pensadores.)

. Ser e tempo. 8a ed., trad. de Márcia Sá Cavalcante Schuback. Petrópolis: Vozes, 2006. 
. “Tempo e ser”, in Heidegger, trad. Ernildo Stein. São Paulo: Abril Cultural, 1979b. (Coleção Os Pensadores.)

SLOTERDIJK, Peter, Sin salvación: Tras las huellas de Heidegger, trad. Joaquín Chamorro Mielke. Madrid: Akal, 2011. 2007.

O sol e a morte, trad. Carlos Correia Monteiro de Oliveira. Lisboa: Relógio D’Água, TSVETÁIEVA, Marina, Vivendo sob o fogo, trad. Aurora Bernardini. São Paulo: Martins Fontes, 2008. 